\title{
Multidrug resistance, inappropriate empiric therapy, and hospital mortality in Acinetobacter baumannii pneumonia and sepsis
}

\author{
Marya D. Zilberberg ${ }^{1 *}$, Brian H. Nathanson ${ }^{2}$, Kate Sulham ${ }^{3}$, Weihong Fan ${ }^{3}$ and Andrew F. Shorr ${ }^{4}$
}

\begin{abstract}
Background: The relationship between multidrug resistance (MDR), inappropriate empiric therapy (IET), and mortality among patients with Acinetobacter baumannii (AB) remains unclear. We examined it using a large U.S. database.
\end{abstract}

Methods: We conducted a retrospective cohort study using the Premier Research database (2009-2013) of 175 U.S. hospitals. We included all adult patients admitted with pneumonia or sepsis as their principal diagnosis, or as a secondary diagnosis in the setting of respiratory failure, along with antibiotic administration within 2 days of admission. Only culture-confirmed infections were included. Resistance to at least three classes of antibiotics defined multidrug-resistant $A B(M D R-A B)$. We used logistic regression to compute the adjusted relative risk ratio (RRR) of patients with MDR-AB receiving IET and IET's impact on mortality.

Results: Among 1423 patients with AB infection, 1171 (82.3\%) had MDR-AB. Those with MDR-AB were older (63.7 \pm 15.4 vs. $61.0 \pm 16.9$ years, $p=0.014)$. Although chronic disease burden did not differ between groups, the MDR-AB group had higher illness severity than those in the non-MDR-AB group (intensive care unit $68.0 \%$ vs. 59 . $5 \%, p<0.001$; mechanical ventilation $56.2 \%$ vs. $42.1 \%, p<0.001)$. Patients with MDR-AB were more likely to receive IET than those in the non-MDR-AB group (76.2 \% MDR-AB vs. $13.8 \%$ non-MDR-AB, $p<0.001$ ). In a regression model, MDR-AB strongly predicted receipt of IET (adjusted RRR 5.5, $95 \% \mathrm{Cl} 4.0-7.7, p<0.001$ ). IET exposure was associated with higher hospital mortality (adjusted RRR 1.8, $95 \% \mathrm{Cl} 1.4-2.3, p<0.001$ ).

Conclusions: In this large U.S. database, the prevalence of MDR-AB among patients with AB infection was $>80 \%$. Harboring MDR-AB increased the risk of receiving IET more than fivefold, and IET nearly doubled hospital mortality.

Keywords: Pneumonia, Sepsis, Acinetobacter baumannii, Multidrug resistance, Inappropriate empiric therapy, Outcomes

\section{Background}

The Centers for Disease Control and Prevention considers Acinetobacter baumannii $(\mathrm{AB})$ a "serious" threat [1]. AB's resistance mechanisms target both first-line and salvage broad-spectrum agents, with approximate doubling in carbapenem and multidrug resistance (MDR) in the United States over the last decade [2, 3]. In addition to its public health implications, the rising tide

\footnotetext{
* Correspondence: evimedgroup@gmail.com

${ }^{1}$ EviMed Research Group, LLC, PO Box 303, Goshen, MA 01032, USA Full list of author information is available at the end of the article
}

of drug resistance presents a difficult clinical conundrum. In serious infections, appropriate initial therapy determines clinical outcomes. However, more extensive drug resistance makes it a challenge to select appropriate treatment [4-13]. Carbapenem resistance among AB in severe sepsis and/or septic shock increases the risk of receiving inappropriate empiric therapy (IET) nearly threefold, raising the risk of death [14]. Unfortunately, using carbapenems as empiric therapy in hopes of minimizing IET drives increasing carbapenem resistance. Because of the limited data on this issue in $\mathrm{AB}$, we conducted 
a multicenter, retrospective cohort study to explore the impact of MDR in IET and of IET on hospital mortality in $\mathrm{AB}$.

\section{Methods}

We conducted a multicenter retrospective cohort study of patients admitted to the hospital with pneumonia and/or sepsis and included in the Premier Research database in the 2009-2013. We hypothesized that multidrug-resistant $\mathrm{AB}$ (MDR-AB) (primary exposure) increases the risk of receiving IET (primary outcome), and that IET increases hospital mortality. Because this study used already-existing, Health Insurance Portability and Accountability Act ("HIPAA")-compliant, fully deidentified data, it was exempt from institutional review board (IRB) review.

\section{Patient population}

Patients were included if they were adults (aged $\geq 18$ years) hospitalized with pneumonia and/or sepsis. Pneumonia was identified by the principal diagnosis International Classification of Diseases, Ninth Revision, Clinical Modification (ICD-9-CM) codes 481-486, or by respiratory failure codes (518.81 or 518.84) with pneumonia as a secondary diagnosis. Sepsis was identified by the principal diagnosis codes $038,038.9,020.0,790.7,995.92$, or 785.52, or by respiratory failure codes (518.81 or 518.84 ) with sepsis as a secondary diagnosis [15-18]. Only patients with community-onset (present on admission) infection and antibiotic treatment beginning within the first 2 hospital days and continued for at least three consecutive days or until discharge were included [15-17]. Patients were excluded if they had been transferred from another acute care facility, had cystic fibrosis, or had a hospital length of stay of 1 day or less. Those with both pneumonia and sepsis were included in the pneumonia group. Patients were followed until death in or discharge from the hospital. Only patients with a positive $A B$ culture from a pulmonary or blood source who met the above criteria were included in the analysis.

\section{Data source}

The Premier Research database, an electronic laboratory, pharmacy, and billing data repository for 2009-2013, contains approximately $15 \%$ of all U.S. hospitalizations nationwide. In addition to patient age, sex, race and/or ethnicity, principal and secondary diagnoses, and procedures, the database contains a date-stamped log of all medications, laboratory tests, and diagnostic and therapeutic services charged to the patient or the patient's insurer. We used data from 176 U.S. institutions that submit microbiological data into the database. Eligible time began only following the commencement of microbiological data submission by each institution.

\section{Baseline variables}

We classified infection (pneumonia or sepsis) as healthcare-associated (HCA) if one or more of the following were present: (1) prior hospitalization within 90 days of the index hospitalization, (2) hemodialysis, (3) admission from a long-term care facility, and/or (4) immune suppression. All other infections were considered communityacquired (CA). Patient-level factors included demographic variables and comorbid conditions. Charlson comorbidity index score was computed as a measure of the burden of chronic illness, while intensive care unit (ICU) admission, mechanical ventilation, and vasopressor use served as markers for disease severity. Hospital-level characteristics examined were geographic region, size, teaching status, and urbanicity.

\section{Microbiological and treatment-related variables and definitions}

Blood and respiratory cultures had to be obtained within the first 2 days of hospitalization. AB isolates were classified as $\mathrm{S}$ (susceptible), I (intermediate), or R (resistant). For the purposes of the present analyses, I and $\mathrm{R}$ were grouped together as nonsusceptible. MDR-AB was defined, per Magiorakos et al., as any $A B$ resistant to at least one agent in at least three antimicrobial classes [19]. Similarly, extensively drug resistant AB (XDR-AB) was defined as an $A B$ resistant to at least one agent in all but two or fewer classes listed above, and pandrugresistant $A B$ (PDR- $A B$ ) as an $A B$ resistant to all antimicrobial agents listed above [19].

IET was present if the antibiotic administered did not cover the organism or if coverage did not start within 2 days of obtaining the positive culture. Because the role of combination therapy in treating $A B$ is not well defined, combination therapy was not included in the definition of IET [20]. IET was deemed "indeterminate" if the susceptibility of $A B$ to the regimen received was not reported. These cases were excluded from the IET analysis. All microbiological testing was performed at the institutions contributing data to the database and conformed to the Clinical \& Laboratory Standards Institute standards.

\section{Statistical analyses}

We compared characteristics of patients infected with MDR-AB with those of patients with non-MDR-AB infection, as well as characteristics of patients who received IET with those of patients treated with non-IET. Continuous variables were reported as means with SD when distributed normally or as medians with 25th and 75th percentiles when skewed. Differences between mean values were tested via Student's $t$ test, and differences between medians were assessed using the Mann-Whitney $U$ test. Categorical data were summarized as proportions, 
Table 1 Baseline characteristics

\begin{tabular}{|c|c|c|c|c|c|}
\hline & Non-MDR-AB $(n=252)$ & $\%$ & $\operatorname{MDR}-\mathrm{AB}(n=1171)$ & $\%$ & $p$ Value \\
\hline Mean age, years (SD) & $61.0(16.9)$ & & $63.7(15.4)$ & & 0.014 \\
\hline Male sex & 134 & $53.2 \%$ & 633 & $54.1 \%$ & 0.799 \\
\hline \multicolumn{6}{|l|}{ Race/ethnicity } \\
\hline White & 134 & $53.2 \%$ & 633 & $54.1 \%$ & $<0.001$ \\
\hline \multicolumn{6}{|l|}{ Black } \\
\hline Hispanic & 159 & $63.1 \%$ & 738 & $63.0 \%$ & \\
\hline Other & 55 & $21.8 \%$ & 276 & $23.6 \%$ & \\
\hline \multicolumn{6}{|l|}{ Admission source } \\
\hline Non-healthcare facility (including from home) & 167 & $66.3 \%$ & 573 & $48.9 \%$ & $<0.001$ \\
\hline Clinic & 14 & $5.6 \%$ & 26 & $2.2 \%$ & \\
\hline Transfer from ECF & 13 & $5.2 \%$ & 280 & $23.9 \%$ & \\
\hline Transfer from another non-acute care facility & 3 & $1.2 \%$ & 45 & $3.8 \%$ & \\
\hline Emergency department & 54 & $21.4 \%$ & 236 & $20.2 \%$ & \\
\hline Other & 1 & $0.4 \%$ & 11 & $1.0 \%$ & \\
\hline \multicolumn{6}{|l|}{ Elixhauser comorbidities } \\
\hline Congestive heart failure & 61 & $24.2 \%$ & 353 & $30.1 \%$ & 0.060 \\
\hline Valvular disease & 21 & $8.3 \%$ & 92 & $7.9 \%$ & 0.800 \\
\hline Pulmonary circulation disease & 16 & $6.3 \%$ & 107 & $9.1 \%$ & 0.153 \\
\hline Peripheral vascular disease & 33 & $13.1 \%$ & 145 & $12.4 \%$ & 0.756 \\
\hline Paralysis & 32 & $12.7 \%$ & 292 & $24.9 \%$ & $<0.001$ \\
\hline Other neurological disorders & 44 & $17.5 \%$ & 300 & $25.6 \%$ & 0.006 \\
\hline Chronic pulmonary disease & 108 & $42.9 \%$ & 507 & $43.3 \%$ & 0.898 \\
\hline Diabetes without chronic complications & 65 & $25.8 \%$ & 390 & $33.3 \%$ & 0.020 \\
\hline Diabetes with chronic complications & 21 & $8.3 \%$ & 96 & $8.2 \%$ & 0.943 \\
\hline Hypothyroidism & 28 & $11.1 \%$ & 182 & $15.5 \%$ & 0.072 \\
\hline Renal failure & 66 & $26.2 \%$ & 359 & $30.7 \%$ & 0.160 \\
\hline Liver disease & 17 & $6.7 \%$ & 37 & $3.2 \%$ & 0.007 \\
\hline Peptic ulcer disease with bleeding & 0 & $0.0 \%$ & 0 & $0.0 \%$ & 1.000 \\
\hline AIDS & 0 & $0.0 \%$ & 0 & $0.0 \%$ & 1.000 \\
\hline Lymphoma & 1 & $0.4 \%$ & 16 & $1.4 \%$ & 0.336 \\
\hline Metastatic cancer & 20 & $7.9 \%$ & 30 & $2.6 \%$ & $<0.001$ \\
\hline Solid tumor without metastasis & 17 & $6.7 \%$ & 31 & $2.6 \%$ & 0.001 \\
\hline Rheumatoid arthritis/collagen vascular & 5 & $2.0 \%$ & 46 & $3.9 \%$ & 0.132 \\
\hline Coagulopathy & 45 & $17.9 \%$ & 134 & $11.4 \%$ & 0.005 \\
\hline Obesity & 41 & $16.3 \%$ & 191 & $16.3 \%$ & 0.987 \\
\hline Weight loss & 49 & $19.4 \%$ & 392 & $33.5 \%$ & $<0.001$ \\
\hline Fluid and electrolyte disorders & 145 & $57.5 \%$ & 628 & $53.6 \%$ & 0.258 \\
\hline Chronic blood loss anemia & 5 & $2.0 \%$ & 16 & $1.4 \%$ & 0.461 \\
\hline Deficiency anemia & 97 & $38.5 \%$ & 593 & $50.6 \%$ & $<0.001$ \\
\hline Alcohol abuse & 22 & $8.7 \%$ & 35 & $3.0 \%$ & $<0.001$ \\
\hline Drug abuse & 16 & $6.3 \%$ & 29 & $2.5 \%$ & 0.001 \\
\hline Psychosis & 13 & $5.2 \%$ & 77 & $6.6 \%$ & 0.402 \\
\hline Depression & 29 & $11.5 \%$ & 161 & $13.7 \%$ & 0.343 \\
\hline Hypertension & 158 & $62.7 \%$ & 669 & $57.1 \%$ & 0.104 \\
\hline
\end{tabular}


Table 1 Baseline characteristics (Continued)

\begin{tabular}{|c|c|c|c|c|c|}
\hline \multicolumn{6}{|c|}{ Charlson comorbidity index score } \\
\hline 0 & 58 & $23.0 \%$ & 247 & $21.1 \%$ & \multirow[t]{6}{*}{0.542} \\
\hline 1 & 60 & $23.8 \%$ & 298 & $25.4 \%$ & \\
\hline 2 & 50 & $19.8 \%$ & 244 & $20.8 \%$ & \\
\hline 3 & 35 & $13.9 \%$ & 179 & $15.3 \%$ & \\
\hline 4 & 21 & $8.3 \%$ & 112 & $9.6 \%$ & \\
\hline $5+$ & 28 & $11.1 \%$ & 91 & $7.8 \%$ & \\
\hline Mean (SD) & $2.2(2.4)$ & & $2.0(1.9)$ & & 0.096 \\
\hline Median [IQR] & $2[1-3]$ & & $2[1-3]$ & & 0.873 \\
\hline \multicolumn{6}{|c|}{ Hospital characteristics } \\
\hline \multicolumn{6}{|c|}{ U.S. census region } \\
\hline Midwest & 49 & $19.4 \%$ & 377 & $32.2 \%$ & \multirow[t]{4}{*}{$<0.001$} \\
\hline Northeast & 54 & $21.4 \%$ & 164 & $14.0 \%$ & \\
\hline South & 122 & $48.4 \%$ & 436 & $37.2 \%$ & \\
\hline West & 27 & $10.7 \%$ & 194 & $16.6 \%$ & \\
\hline \multicolumn{6}{|c|}{ Number of beds } \\
\hline$<200$ & 26 & $10.3 \%$ & 140 & $12.0 \%$ & \multirow[t]{4}{*}{0.007} \\
\hline 200-299 & 49 & $19.4 \%$ & 272 & $23.2 \%$ & \\
\hline $300-499$ & 84 & $33.3 \%$ & 454 & $38.8 \%$ & \\
\hline $500+$ & 93 & $36.9 \%$ & 305 & $26.0 \%$ & \\
\hline Teaching & 137 & $54.4 \%$ & 537 & $45.9 \%$ & 0.014 \\
\hline Urban & 233 & $92.5 \%$ & 1135 & $96.9 \%$ & 0.001 \\
\hline
\end{tabular}

MDR-AB multidrug-resistant Acinetobacter baumannii, ECF extended care facility

and chi-square test or Fisher's exact test (when cell counts were $\leq 4$ ) was used to examine differences between groups.

We developed a generalized logistic regression model to explore the relationship between MDR-AB and the risk of IET. Covariates in the model included demographics (sex, age, whether the infection was HCA), Elixhauser comorbidities, and measures of illness severity by hospital day 2 . We calculated the relative risk ratio with $95 \% \mathrm{CI}$ of receiving IET for MDR-AB vs. non-MDR-AB, based on Huber-White robust standard errors clustered at the hospital level [21]. To confirm our results, we created two other models: (1) a nonparse model that included all of the predictors in the generalized logistic regression model with a large number of additional treatments present or absent by hospital day 2 , and (2) a propensity-matched model with propensity for MDR-AB derived from a logistic regression model using the nonparse model's predictors, and MDR-AB matched to non-MDR-AB patients using a 5:1 Greedy algorithm [22, 23].

All tests were two-tailed, and a $p$ value $<0.05$ was deemed a priori to represent statistical significance. All analyses were performed in Stata/MP 13.1 for Windows software (StataCorp LP, College Station, TX, USA).

\section{Results}

Among the 229,028 enrolled patients with pneumonia or sepsis, $1423(0.6 \%)$ had a pulmonary or blood culture positive for $\mathrm{AB}$, of which 1171 (82.3\%) were MDR, 239 $(16.8 \%)$ were XDR, and $0(0.0 \%)$ were PDR. Patients with MDR-AB were older $(63.7 \pm 15.4$ vs. $61.0 \pm 16.9$ years, $p=0.014)$ than those with non-MDR-AB, while the racial distributions were comparable in both groups (Table 1). Although the distribution of some chronic conditions varied, there was no difference between the groups in the Charlson comorbidity index (Table 1). MDR-AB was more common than non-MDR-AB in the West and the Midwest, in urban hospitals, and in hospitals of medium size (200-499 beds). Both large hospitals (500+ beds) and those with an academic program were less likely to have MDR-AB than non-MDR-AB (Table 1).

In both groups (MDR-AB and non-MDR-AB), the majority (approximately three-fourths) of the patients had a diagnosis of sepsis, with the remaining one-fourth having pneumonia (Table 2). Patients harboring MDR-AB were more likely to have an HCA infection (64.9 \% vs. $42.5 \%, p<0.001$ ) along with higher illness severity by day 2 of admission (ICU $68.0 \%$ vs. $59.5 \%, p<0.001$; mechanical ventilation $56.2 \%$ vs. $42.1 \%, p<0.001$; vasopressors 
Table 2 Infection characteristics and treatment

\begin{tabular}{|c|c|c|c|c|c|}
\hline & Non-MDR-AB $(n=252)$ & $\%$ & $\operatorname{MDR}-\mathrm{AB}(n=1171)$ & $\%$ & $p$ Value \\
\hline \multicolumn{6}{|l|}{ Infection characteristics } \\
\hline Sepsis & 184 & $73.0 \%$ & 875 & $74.7 \%$ & 0.573 \\
\hline Pneumonia & 68 & $27.0 \%$ & 296 & $25.3 \%$ & \\
\hline HCA & 107 & $42.5 \%$ & 760 & $64.9 \%$ & $<0.001$ \\
\hline \multicolumn{6}{|l|}{ IIIness severity measures by day 2} \\
\hline ICU admission & 150 & $59.5 \%$ & 796 & $68.0 \%$ & 0.010 \\
\hline Mechanical ventilation & 106 & $42.1 \%$ & 658 & $56.2 \%$ & $<0.001$ \\
\hline Vasopressors & 39 & $15.5 \%$ & 206 & $17.6 \%$ & 0.420 \\
\hline \multicolumn{6}{|l|}{ Antibiotics administered by day 2} \\
\hline Antipseudomonal penicillins with $\beta$-lactamase inhibitor & 140 & $55.6 \%$ & 588 & $50.2 \%$ & 0.124 \\
\hline Extended-spectrum cephalosporins & 100 & $39.7 \%$ & 373 & $31.9 \%$ & 0.017 \\
\hline Antipseudomonal fluoroquinolones & 96 & $38.1 \%$ & 489 & $41.8 \%$ & 0.284 \\
\hline Antipseudomonal carbapenems & 37 & $14.7 \%$ & 350 & $29.9 \%$ & $<0.001$ \\
\hline Aminoglycosides & 25 & $9.9 \%$ & 204 & $17.4 \%$ & 0.003 \\
\hline Penicillins with $\beta$-lactamase inhibitors & 4 & $1.6 \%$ & 19 & $1.6 \%$ & 1.000 \\
\hline Tetracyclines & 3 & $1.2 \%$ & 6 & $0.5 \%$ & 0.203 \\
\hline Folate pathway inhibitors & 3 & $1.2 \%$ & 11 & $0.9 \%$ & 0.724 \\
\hline Polymyxins & 0 & $0.0 \%$ & 37 & $3.2 \%$ & 0.001 \\
\hline \multicolumn{6}{|l|}{ Empiric treatment appropriateness } \\
\hline Non-IET & 162 & $64.3 \%$ & 217 & $18.5 \%$ & $<0.001$ \\
\hline IET & 26 & $10.3 \%$ & 693 & $59.2 \%$ & \\
\hline Indeterminate & 64 & $25.4 \%$ & 261 & $22.3 \%$ & \\
\hline
\end{tabular}

Abbreviations: MDR-AB multidrug-resistant Acinetobacter baumannii, $H C A$ healthcare-associated, ICU intensive care unit, IET inappropriate empiric therapy

$15.5 \%$ vs. $17.6 \%, p=0.420)$ than non-MDR-AB patients (Table 2). Although patients in the MDR-AB group had a higher prevalence of use of antipseudomonal carbapenems, aminoglycosides, and polymyxins than those in the non-MDR-AB group, they were also far more likely to receive IET (76.2 \% MDR-AB vs. $13.8 \%$ non-MDR-AB, $p<0.001$ ), regardless of infection type (Fig. 1). Unadjusted

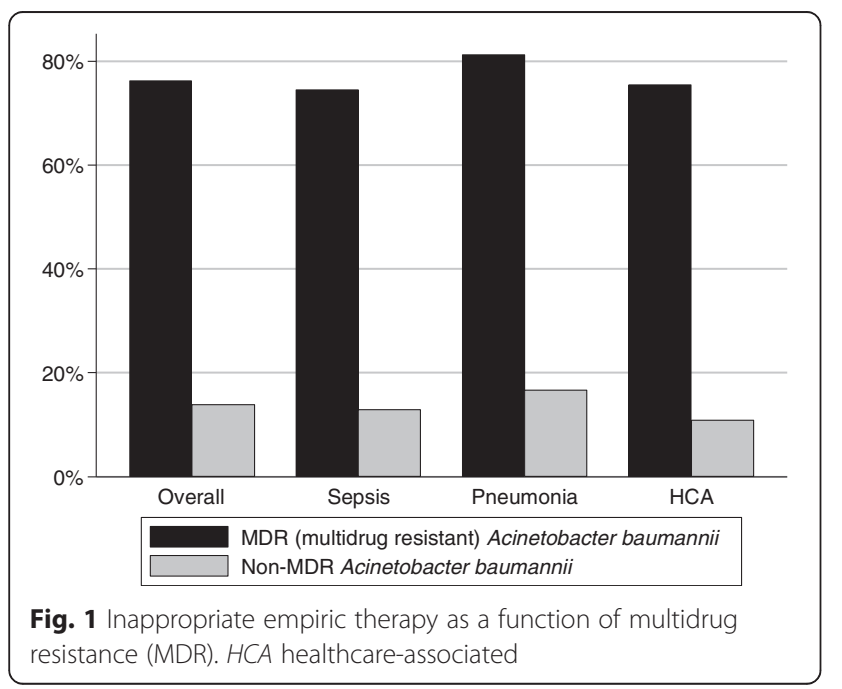

hospital mortality among patients with MDR-AB was nearly double that in those with non-MDR-AB (23.7 \% vs. $12.7 \%, p<0.001)$.

When we compared the cohort of 1098 patients $(77.2 \%$ of all $A B$ patients) with valid, known antimicrobial treatment data based on the receipt of IET, we found that only 379 (34.5\%) received appropriate therapy (Table 3). The rate of sepsis upon admission did not significantly differ between IET and non-IET patients (Table 3). Unadjusted hospital mortality was higher in patients receiving IET than non-IET ( $23.6 \%$ vs. $16.6 \%, p=0.007)$ in all infection types (Fig. 2).

In a regression model designed to explore the impact of MDR on the risk of IET exposure, MDR-AB was the single strongest predictor of receiving IET (adjusted relative risk ratio $5.5,95 \%$ CI $4.0-7.7, p<0.001$ ) (Table 4). The confirmatory analyses produced similar risk ratios (Table 4).

In a nonparse generalized regression model adjusting for all confounders (demographics, comorbidities, severity of illness measures, hospital characteristics), IET was associated with an increased risk of in-hospital mortality (adjusted relative risk ratio 1.76; $95 \%$ CI 1.36-2.28, $p<0.001$ (Table 4). The parse model and propensitymatched analysis produced similar risk ratios. 
Table 3 Characteristics of the cohort, based on receipt of inappropriate empiric therapy

\begin{tabular}{|c|c|c|c|c|c|}
\hline & Non-IET $(n=379)$ & $\%$ & $\mathrm{IET}(n=719)$ & $\%$ & $p$ Value \\
\hline \multicolumn{6}{|l|}{ Baseline characteristics } \\
\hline Mean age, years (SD) & $62.4(15.6)$ & & $62.7(15.9)$ & & 0.767 \\
\hline Male sex & 202 & $53.3 \%$ & 373 & $51.9 \%$ & 0.654 \\
\hline \multicolumn{6}{|l|}{ Race/ethnicity } \\
\hline White & 236 & $62.3 \%$ & 464 & $64.5 \%$ & \multirow[t]{4}{*}{0.055} \\
\hline Black & 103 & $27.2 \%$ & 159 & $22.1 \%$ & \\
\hline Hispanic & 7 & $1.8 \%$ & 32 & $4.5 \%$ & \\
\hline Other & 33 & $8.7 \%$ & 64 & $8.9 \%$ & \\
\hline \multicolumn{6}{|l|}{ Admission source } \\
\hline Non-healthcare facility (including from home) & 223 & $58.8 \%$ & 357 & $49.7 \%$ & \multirow[t]{6}{*}{0.022} \\
\hline Clinic & 14 & $3.7 \%$ & 15 & $2.1 \%$ & \\
\hline Transfer from ECF & 69 & $18.2 \%$ & 173 & $24.1 \%$ & \\
\hline Transfer from another non-acute care facility & 8 & $2.1 \%$ & 20 & $2.8 \%$ & \\
\hline Emergency department & 63 & $16.6 \%$ & 148 & $20.6 \%$ & \\
\hline Other & 2 & $0.5 \%$ & 6 & $0.9 \%$ & \\
\hline \multicolumn{6}{|l|}{ Elixhauser comorbidities } \\
\hline Congestive heart failure & 97 & $21.5 \%$ & 209 & $30.4 \%$ & 0.222 \\
\hline Valvular disease & 30 & $6.6 \%$ & 53 & $7.7 \%$ & 0.746 \\
\hline Pulmonary circulation disease & 26 & $5.8 \%$ & 62 & $9.0 \%$ & 0.306 \\
\hline Peripheral vascular disease & 51 & $11.3 \%$ & 82 & $11.9 \%$ & 0.322 \\
\hline Paralysis & 85 & $18.8 \%$ & 176 & $25.6 \%$ & 0.448 \\
\hline Other neurological disorders & 82 & $18.1 \%$ & 185 & $26.9 \%$ & 0.133 \\
\hline Chronic pulmonary disease & 164 & $36.3 \%$ & 305 & $44.4 \%$ & 0.786 \\
\hline Diabetes without chronic complications & 105 & $23.2 \%$ & 241 & $35.1 \%$ & 0.049 \\
\hline Diabetes with chronic complications & 38 & $8.4 \%$ & 56 & $8.2 \%$ & 0.208 \\
\hline Hypothyroidism & 49 & $10.8 \%$ & 119 & $17.3 \%$ & 0.113 \\
\hline Renal failure & 107 & $23.7 \%$ & 217 & $31.6 \%$ & 0.501 \\
\hline Liver disease & 17 & $3.8 \%$ & 27 & $3.9 \%$ & 0.557 \\
\hline Peptic ulcer disease with bleeding & 0 & $0.0 \%$ & 0 & $0.0 \%$ & 1.000 \\
\hline AIDS & 0 & $0.0 \%$ & 0 & $0.0 \%$ & 1.000 \\
\hline Lymphoma & 2 & $0.4 \%$ & 10 & $1.5 \%$ & 0.236 \\
\hline Metastatic cancer & 24 & $5.3 \%$ & 17 & $2.5 \%$ & 0.001 \\
\hline Solid tumor without metastasis & 18 & $4.0 \%$ & 19 & $2.8 \%$ & 0.066 \\
\hline Rheumatoid arthritis/collagen vascular & 11 & $2.4 \%$ & 29 & $4.2 \%$ & 0.342 \\
\hline Coagulopathy & 58 & $12.8 \%$ & 83 & $12.1 \%$ & 0.077 \\
\hline Obesity & 48 & $10.6 \%$ & 128 & $18.6 \%$ & 0.027 \\
\hline Weight loss & 94 & $20.8 \%$ & 250 & $36.4 \%$ & 0.001 \\
\hline Fluid and electrolyte disorders & 219 & $48.5 \%$ & 393 & $57.2 \%$ & 0.322 \\
\hline Chronic blood loss anemia & 5 & $1.1 \%$ & 9 & $1.3 \%$ & 0.924 \\
\hline Deficiency anemia & 173 & $38.3 \%$ & 363 & $52.8 \%$ & 0.127 \\
\hline Alcohol abuse & 18 & $4.0 \%$ & 24 & $3.5 \%$ & 0.246 \\
\hline Drug abuse & 16 & $3.5 \%$ & 19 & $2.8 \%$ & 0.157 \\
\hline Psychosis & 22 & $4.9 \%$ & 45 & $6.6 \%$ & 0.765 \\
\hline Depression & 50 & $11.1 \%$ & 96 & $14.0 \%$ & 0.941 \\
\hline Hypertension & 215 & $47.6 \%$ & 413 & $60.1 \%$ & 0.821 \\
\hline
\end{tabular}


Table 3 Characteristics of the cohort, based on receipt of inappropriate empiric therapy (Continued)

\begin{tabular}{|c|c|c|c|c|c|}
\hline \multicolumn{6}{|l|}{ Charlson comorbidity score } \\
\hline 0 & 72 & $19.0 \%$ & 164 & $22.8 \%$ & \multirow[t]{6}{*}{0.152} \\
\hline 1 & 108 & $28.5 \%$ & 177 & $24.6 \%$ & \\
\hline 2 & 64 & $16.9 \%$ & 151 & $21.0 \%$ & \\
\hline 3 & 62 & $16.4 \%$ & 108 & $15.0 \%$ & \\
\hline 4 & 34 & $9.0 \%$ & 66 & $9.2 \%$ & \\
\hline $5+$ & 39 & $10.3 \%$ & 53 & $7.4 \%$ & \\
\hline Mean (SD) & $2.2(2.2)$ & & $2.0(1.9)$ & & 0.043 \\
\hline Median [IQR] & $2[1-3]$ & & $2[1-3]$ & & 0.202 \\
\hline \multicolumn{6}{|l|}{ Infection characteristics and treatments } \\
\hline \multicolumn{6}{|l|}{ Infection characteristics } \\
\hline Sepsis & 296 & $78.1 \%$ & 525 & $73.0 \%$ & \multirow[t]{2}{*}{0.065} \\
\hline Pneumonia & 83 & $21.9 \%$ & 194 & $27.0 \%$ & \\
\hline $\mathrm{HCA}$ & 222 & $58.6 \%$ & 464 & $64.5 \%$ & 0.053 \\
\hline MDR-AB & 217 & $57.3 \%$ & 693 & $96.4 \%$ & $<0.001$ \\
\hline \multicolumn{6}{|l|}{ IIIness severity } \\
\hline ICU admission & 249 & $65.7 \%$ & 482 & $67.0 \%$ & 0.655 \\
\hline Mechanical ventilation & 206 & $54.4 \%$ & 390 & $54.2 \%$ & 0.972 \\
\hline Vasopressors & 64 & $16.9 \%$ & 121 & $16.8 \%$ & 0.981 \\
\hline \multicolumn{6}{|l|}{ Antibiotics administered } \\
\hline Antipseudomonal penicillins with $\beta$-lactamase inhibitor & 91 & $24.0 \%$ & 123 & $17.1 \%$ & 0.006 \\
\hline Antipseudomonal fluoroquinolones & 97 & $25.6 \%$ & 209 & $29.1 \%$ & 0.222 \\
\hline Extended-spectrum cephalosporins & 177 & $46.7 \%$ & 339 & $47.1 \%$ & 0.888 \\
\hline Antipseudomonal carbapenems & 190 & $50.1 \%$ & 350 & $48.7 \%$ & 0.647 \\
\hline Aminoglycosides & 140 & $36.9 \%$ & 269 & $37.4 \%$ & 0.877 \\
\hline Penicillins with $\beta$-lactamase inhibitors & 5 & $1.3 \%$ & 9 & $1.3 \%$ & 0.924 \\
\hline Polymyxins & 12 & $3.2 \%$ & 9 & $1.3 \%$ & 0.028 \\
\hline Folate pathway inhibitors & 7 & $1.8 \%$ & 23 & $3.2 \%$ & 0.191 \\
\hline Tetracyclines & 1 & $0.3 \%$ & 4 & $0.6 \%$ & 0.665 \\
\hline \multicolumn{6}{|l|}{ Hospital characteristics } \\
\hline \multicolumn{6}{|l|}{ U.S. region } \\
\hline Midwest & 118 & $31.1 \%$ & 234 & $32.5 \%$ & \multirow[t]{4}{*}{$<0.001$} \\
\hline Northeast & 60 & $15.8 \%$ & 91 & $12.7 \%$ & \\
\hline South & 167 & $44.1 \%$ & 254 & $35.3 \%$ & \\
\hline West & 34 & $9.0 \%$ & 140 & $19.5 \%$ & \\
\hline \multicolumn{6}{|l|}{ Number of beds } \\
\hline$<200$ & 41 & $10.8 \%$ & 78 & $10.8 \%$ & \multirow[t]{4}{*}{0.011} \\
\hline 200-299 & 65 & $17.2 \%$ & 165 & $22.9 \%$ & \\
\hline $300-499$ & 143 & $37.7 \%$ & 292 & $40.6 \%$ & \\
\hline $500+$ & 130 & $34.3 \%$ & 184 & $25.6 \%$ & \\
\hline Teaching & 212 & $55.9 \%$ & 292 & $40.6 \%$ & $<0.001$ \\
\hline Urban & 357 & $94.2 \%$ & 696 & $96.8 \%$ & 0.038 \\
\hline Hospital mortality & 63 & $16.6 \%$ & 170 & $23.6 \%$ & 0.007 \\
\hline
\end{tabular}

Abbreviations: IET inappropriate empiric therapy, ECF extended care facility, HCA healthcare-associated, MDR-AB multidrug-resistant Acinetobacter baumannii, ICU intensive care unit 


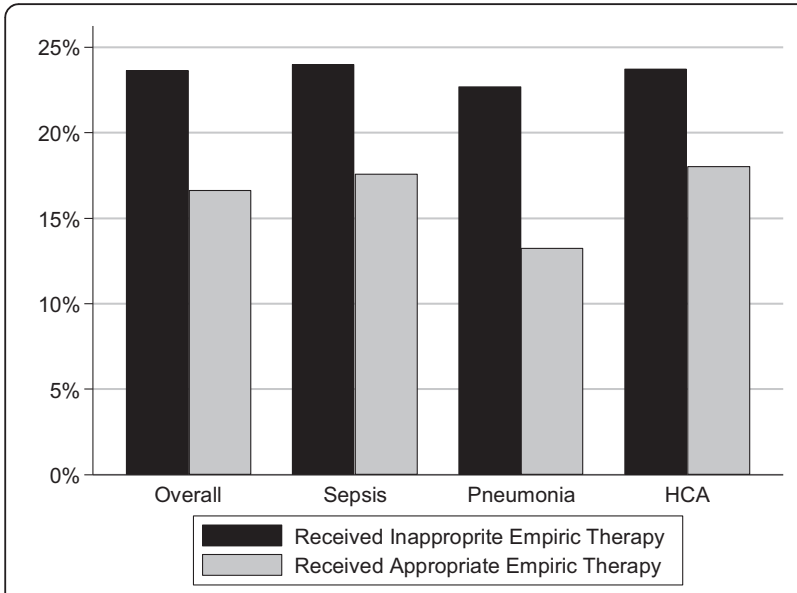

Fig. 2 Mortality and inappropriate empiric therapy. HCA healthcare-associated

\section{Discussion}

In this large, multicenter cohort study, we have demonstrated that $\mathrm{CA}$ and HCA pneumonia and sepsis are rarely caused by $\mathrm{AB}$. However, when $\mathrm{AB}$ is present, it is most often MDR. Moreover, harboring MDR puts patients at a fivefold increased risk of receiving IET, which is in turn associated with increased hospital mortality.

Multiple investigators have documented the exceedingly high and rising rate of $\mathrm{AB}$ resistance. In a multicenter microbiology database study in the United States, we noted a rise in MDR-AB from $21.4 \%$ between 2003 and 2005 to $35.2 \%$ in the 2009-2012 period [3]. Similarly, the Center for Disease Dynamics, Economics \& Policy (CDDEP) reported an MDR-AB increase from $32.1 \%$ in 2009 to $51.0 \%$ in 2010 [2]. The discrepancy between the two studies reflects the populations evaluated and the definitions of MDR applied. While our prior investigation was limited to only patients with severe sepsis and septic shock, the CDDEP surveillance included all infection sources. Additionally, we limited drug definitions to those where clinical efficacy data were available, while CDDEP included all pertinent drug categories.

Our present study, though not longitudinal, confirms the high probability of MDR-AB, though the rate is higher than that in either of the surveillance studies. Although the our examined population is more similar to that in our previous surveillance study than to the CDDEP surveillance, the IET definition is more in line with that of the CDDEP [19]. Because our data represent years 2009-2013, the high prevalence may simply be consistent with continued growth of this resistant pathogen beyond the time frame examined in either of the previous surveillance efforts.

We confirm that antimicrobial resistance confers a high risk for IET. A previous single-center study reported that having severe sepsis or septic shock caused by carbapenem-resistant $A B$ doubled the risk of IET [14]. This is the case for any gram-negative pathogen of severe sepsis or septic shock [24]. In the present study, the effect size was even greater, with a more than fivefold increase in the relative risk of receiving IET compared with nonMDR-AB. This suggests that clinicians should consider broad empiric coverage when $A B$ is either suspected or identified by rapid testing.

In sepsis and pneumonia, it has been shown repeatedly that IET increases hospital mortality two- to fourfold and that escalation of treatment in response to culture results fails to alter this outcome [4-13]. Specific to $A B$ sepsis and septic shock patients, Shorr et al. recently reported a significantly elevated risk of mortality associated with IET (risk ratio 1.42, $95 \%$ CI 1.10-1.58, $p=0.015$ ) [14]. We confirm this observation in a cohort of patients with $\mathrm{AB}$ pneumonia or sepsis. However, this association

Table 4 Adjusted risk of inappropriate empiric therapy and hospital mortality

\begin{tabular}{|c|c|c|c|c|}
\hline Risk of IET in the setting of MDR-AB & $\begin{array}{l}\text { Marginal effect, IET in } \\
\text { non-MDR-AB }\end{array}$ & $\begin{array}{l}\text { Marginal effect, } \\
\text { IET in MDR-AB }\end{array}$ & $\begin{array}{l}\text { Adjusted relative risk ratio } \\
(95 \% \mathrm{Cl})\end{array}$ & $p$ Value \\
\hline \multicolumn{5}{|l|}{ Method } \\
\hline Parse model & $13.8 \%$ & $76.2 \%$ & $5.5(4.0-7.7)$ & $<0.001$ \\
\hline $\begin{array}{l}\text { Propensity score (based on } 204 \text { matched pairs; } \\
81.0 \% \text { matched) }\end{array}$ & $13.4 \%$ & $73.9 \%$ & $5.5(3.6-8.4)$ & $<0.001$ \\
\hline Nonparse model & $14.4 \%$ & $75.6 \%$ & $5.3(3.7-7.4)$ & $<0.001$ \\
\hline Risk of death in the setting of IET & $\begin{array}{l}\text { Marginal effect, mortality } \\
\text { in non-IET }\end{array}$ & $\begin{array}{l}\text { Marginal effect, mortality } \\
\text { in IET }\end{array}$ & $\begin{array}{l}\text { Adjusted relative risk ratio } \\
(95 \% \mathrm{Cl})\end{array}$ & $p$ Value \\
\hline \multicolumn{5}{|l|}{ Method } \\
\hline Parse model & $15.9 \%$ & $24.3 \%$ & $1.53(1.21-1.93)$ & $<0.001$ \\
\hline $\begin{array}{l}\text { Propensity score (based on } 226 \text { matched pairs; } \\
59.6 \% \text { matched) }\end{array}$ & $15.0 \%$ & $27.8 \%$ & $1.85(1.35-2.54)$ & $<0.001$ \\
\hline Nonparse model & $14.5 \%$ & $25.6 \%$ & $1.76(1.36-2.28)$ & $<0.001$ \\
\hline
\end{tabular}

IET inappropriate empiric therapy, MDR-AB multidrug-resistant Acinetobacter baumannii 
has not always been found in studies of $A B$ infection. While researchers in two additional cohort studies reported a two- to sixfold rise in hospital mortality in association with IET for $A B$, six other study groups failed to detect such an association [25-32]. Though it is not clear why such a well-recognized relationship would not exist specifically in the setting of $A B$, there are a number of potential reasons for this divergence. Some of the previous studies suffer from several methodological issues, such as small sample size, incomplete adjustment for or unmeasured confounders, and overadjusting for some factors that may be collinear.

Our study has a number of strengths and limitations. It included a large multicenter cohort representative of U.S. institutions and thus has broad generalizability. Though largely representative of U.S. institutions overall, the southern portion of the United States is overrepresented in the database. Although this made the study susceptible to bias, particularly selection bias, we dealt with it by setting a priori enrollment criteria and definitions for the main exposures and outcomes. Though some misclassification is possible, the main exposures (MDR-AB, IET) and outcomes (IET, hospital mortality) are minimally susceptible to misclassification. At the same time, in at least some of the identified cases, $A B$ might have represented colonization rather than true infection. Additionally, the fact that fully one-third of all MDR-AB were isolates from cases defined as $C A$ suggests that some misclassification may exist in this group; that is, it is possible that we were unable to identify these patients' exposure to the healthcare system with the variables available in the current database. Although confounding is a potential issue in observational studies, we attempted to eliminate this through regression analyses using a large number of potentially confounding variables. Nevertheless, the possibility of residual confounding remains.

\section{Conclusions}

In this largest representative multicenter study to date, although $\mathrm{AB}$ was a rare pathogen in $\mathrm{CA}$ or HCA pneumonia or sepsis, over $80 \%$ of the $\mathrm{AB}$ isolates exhibited MDR. MDR increased the risk of receiving IET fivefold. In turn, IET was associated with increased risk of inhospital mortality.

\section{Key messages}

- $\mathrm{AB}$ is a rare pathogen in community-acquired or healthcare-associated pneumonia or sepsis.

- Eighty percent of all $\mathrm{AB}$ in this population is MDR.

- MDR raises the risk of receiving inappropriate empiric therapy fivefold.

- Inappropriate empiric therapy increases the risk of hospital mortality.

\section{Abbreviations}

AB, Acinetobacter baumannii; CA, community-acquired; CDDEP, Center for Disease Dynamics, Economics \& Policy; ECF, extended care facility; HCA, healthcare-associated; I, intermediate; ICU, intensive care unit; IET, inappropriate empiric therapy; IRB, institutional review board; $M D R$, multidrug resistance; PDR, pandrug-resistant; $R$, resistant;

$R R R$, relative risk ratio; $S$, susceptible; $X D R$, extensively drug resistant

\section{Funding}

This study was supported by a grant from The Medicines Company, Parsippany, NJ, USA

\section{Authors' contributions}

MDZ, KS, WF, and AFS contributed substantially to the study design, the data interpretation, and the writing of the manuscript. BHN had full access to all of the data in the study and takes responsibility for the integrity of the data and the accuracy of the data analysis. BHN contributed substantially to the study design, the data analysis, and the writing of the manuscript. All authors read and approved the final manuscript.

\section{Competing interests}

MDZ, an employee of EviMed Research Group, LLC, has served as a consultant to and/or received research funding from The Medicines Company, Pfizer, Astellas, Tetraphase, Theravance, and Merck. BHN in an employee of OptiStatim, which has received funding from EviMed Research Group, LLC, to conduct this study. KS is an employee and stockholder of The Medicines Company. WF is an employee and stockholder of The Medicines Company. Although KS and WF are employees of the sponsor and participated in the study as coinvestigators, the larger sponsor had no role in the study design, the data analysis or interpretation, or publication decisions. AFS has served as a consultant to, received research support from, or been a speaker for Abbott, Actavis, Alios BioPharma, Astellas Pharma, AstraZeneca, Bayer, Bristol-Myers Squibb, Cardeas Pharma, The Medicines Company, Merck, Pfizer, Roche, Tetraphase Pharmaceuticals, Theravance Biopharma, and Wockhardt Pharma.

\section{Consent for publication}

All authors have reviewed and approved the manuscript for publication.

Ethical approval and consent to participate

Because this study used already-existing, HIPAA-compliant, fully de-identified data, it was exempt from IRB review.

\section{Author details}

${ }^{1}$ EviMed Research Group, LLC, PO Box 303, Goshen, MA 01032, USA. ${ }^{2}$ OptiStatim, LLC, Longmeadow, MA, USA. ${ }^{3}$ The Medicines Company, Parsippany, NJ, USA. "Washington Hospital Center, 110 Irving Street NW, Washington, DC 20010, USA.

Received: 5 May 2016 Accepted: 23 June 2016

Published online: 11 July 2016

\section{References}

1. Centers for Disease Control and Prevention (CDC). Antibiotic resistance threats in the United States, 2013. Atlanta, GA: CDC; 23 Apr 2013. p. 59. Available at http://www.cdc.gov/drugresistance/threat-report-2013/pdf/ ar-threats-2013-508.pdf\#page=59. Accessed 8 Jan 2015.

2. The Center for Disease Dynamics, Economics and Policy (CDDEP). Resistance map: Acinetobacter baumannii overview. Available at http://www.cddep.org/ projects/resistance_map/acinetobacter_baumannii_overview. Accessed 8 Jan 2016.

3. Zilberberg MD, Kollef MH, Shorr AF. Secular trends in Acinetobacter baumannii resistance in respiratory and blood stream specimens in the United States, 2003 to 2012: a survey study. J Hosp Med. 2016;11:21-6.

4. Micek ST, Kollef KE, Reichley RM, Roubinian N, Kollef MH. Health careassociated pneumonia and community-acquired pneumonia: a singlecenter experience. Antimicrob Agents Chemother. 2007:51:3568-73.

5. Iregui M, Ward S, Sherman G, Fraser VJ, Kollef MH. Clinical importance of delays in the initiation of appropriate antibiotic treatment for ventilator-associated pneumonia. Chest. 2002;122:262-8. 
6. Alvarez-Lerma F, ICU-Acquired Pneumonia Study Group. Modification of empiric antibiotic treatment in patients with pneumonia acquired in the intensive care unit. Intensive Care Med. 1996;22:387-94.

7. Zilberberg MD, Shorr AF, Micek MT, Mody SH, Kollef MH. Antimicrobia therapy escalation and hospital mortality among patients with HCAP: a single center experience. Chest. 2008;134:963-8.

8. Dellinger RP, Levy MM, Carlet JM, Bion J, Parker MM, Jaeschke R, et al. Surviving Sepsis Campaign: international guidelines for management of severe sepsis and septic shock: 2008. Crit Care Med. 2008;36:296-327.

9. Shorr AF, Micek ST, Welch EC, Doherty JA, Reichley RM, Kollef MH. Inappropriate antibiotic therapy in Gram-negative sepsis increases hospita length of stay. Crit Care Med. 2011;39:46-51.

10. Kollef MH, Sherman G, Ward S, Fraser VJ. Inadequate antimicrobial treatment of infections: a risk factor for hospital mortality among critically ill patients. Chest. 1999:115:462-74.

11. Garnacho-Montero J, Garcia-Garmendia JL, Barrero-Almodovar A, Jimenez-Jimenez FJ, Perez-Paredes C, Ortiz-Leyba C. Impact of adequate empirical antibiotic therapy on the outcome of patients admitted to the intensive care unit with sepsis. Crit Care Med. 2003;31:2742-51.

12. Harbarth S, Garbino J, Pugin J, Romand JA, Lew D, Pittet D. Inappropriate initial antimicrobial therapy and its effect on survival in a clinical trial of immunomodulating therapy for severe sepsis. Am J Med. 2003;115:529-35.

13. Ferrer R, Artigas A, Suarez D, Palencia E, Levy MM, Arenzana A, et al. Effectiveness of treatments for severe sepsis: a prospective, multicenter, observational study. Am J Respir Crit Care Med. 2009;180:861-6.

14. Shorr AF, Zilberberg MD, Micek ST, Kollef MH. Predictors of hospital mortality among septic ICU patients with Acinetobacter spp. bacteremia: a cohort study. BMC Infect Dis. 2014;14:572.

15. Rothberg MB, Pekow PS, Priya A, Zilberberg MD, Belforti R, Skiest $D$, et al. Using highly detailed administrative data to predict pneumonia mortality. PLoS One. 2014;9:e87382.

16. Rothberg MB, Haessler S, Lagu T, Lindenauer PK, Pekow PS, Priya A, et al. Outcomes of patients with healthcare-associated pneumonia: worse disease or sicker patients? Infect Control Hosp Epidemiol. 2014;35 Suppl 3:S107-15.

17. Rothberg MB, Zilberberg MD, Pekow PS, Priya A, Haessler S, Belforti R, et al. Association of guideline-based antimicrobial therapy and outcomes in healthcare-associated pneumonia. J Antimicrob Chemother. 2015:70:1573-9.

18. Martin GS, Mannino DM, Eaton S, Moss M. The epidemiology of sepsis in the United States from 1979 through 2000. N Engl J Med. 2003:348:1546-54.

19. Magiorakos AP, Srinivasan A, Carey RB, Carmeli Y, Falagas ME, Giske CG, et al. Multidrug-resistant, extensively drug-resistant and pandrug-resistant bacteria: an international expert proposal for interim standard definitions for acquired resistance. Clin Microbiol Infect. 2012;18:268-81.

20. Liu Q, Li W, Feng Y, Tao C. Efficacy and safety of P \polymyxins for the treatment of Acinetobacter baumannii infection: a systematic review and meta-analysis. PLoS One. 2014;9:e98091.

21. Williams RL. A note on robust variance estimation for cluster-correlated data. Biometrics. 2000;56:645-6.

22. Parsons LS. Reducing bias in a propensity score matched-pair sample using greedy matching techniques. Paper 214-26. In: Proceedings of the twenty-sixth annual SAS users group international conference. Cary, NC: SAS Institute; 2001

23. Guo S, Fraser MW. Propensity score analysis: statistical methods and applications. 2nd ed. Thousand Oaks, CA: Sage Publications; 2014.

24. Zilberberg MD, Shorr AF, Micek ST, Vazquez-Guillamet C, Kollef MH. Multi-drug resistance, inappropriate initial antibiotic therapy and mortality in Gram-negative severe sepsis and septic shock: a retrospective cohort study. Crit Care. 2014;18:596.

25. Kwon KT, Oh WS, Song JH, Chang HH, Jung SI, Kim SW, et al. Impact of imipenem resistance on mortality in patients with Acinetobacter bacteraemia. J Antimicrob Chemother. 2007;59:525-30.

26. Erbay A, Idil A, Gozel MG, Mumcuoglu I, Balaban N. Impact of early appropriate antimicrobial therapy on survival in Acinetobacter baumannii bloodstream infections. Int J Antimicrob Agents. 2009;34:575-9.

27. Sunenshine $R H$, Wright MO, Maragakis LL, Harris AD, Song X, Hebden J, et al. Multidrug-resistant Acinetobacter infection mortality rate and length of hospitalization. Emerg Infect Dis. 2007;13:97-103.

28. Chen HP, Chen TL, Lai CH, Fung CP, Wong WW, Yu KW, et al. Predictors of mortality in Acinetobacter baumannii bacteremia. J Microbiol Immunol Infect. 2005;38:127-36.
29. Choi JY, Park YS, Kim CO, Park YS, Yoon HJ, Shin SY, et al. Mortality risk factors of Acinetobacter baumannii bacteraemia. Intern Med J. 2005:35:599-603.

30. Falagas ME, Kasiakou SK, Rafailidis PI, Zouglakis G, Morfou P. Comparison of mortality of patients with Acinetobacter baumannii bacteraemia receiving appropriate and inappropriate empirical therapy. J Antimicrob Chemother. 2006;57:1251-4

31. Metan G, Sariguzel F, Sumerkan B. Factors influencing survival in patients with multi-drug-resistant Acinetobacter bacteraemia. Eur J Intern Med. 2009;20:540-4.

32. Esterly JS, Griffith M, Qi C, Manczynski M, Postelnick MJ, Scheetz MH. Impact of carbapenem resistance and receipt of active antimicrobial therapy on clinical outcomes of Acinetobacter baumannii bloodstream infections. Antimicrob Agents Chemother. 2011;55:4844-9.

\section{Submit your next manuscript to BioMed Central and we will help you at every step:}

- We accept pre-submission inquiries

- Our selector tool helps you to find the most relevant journal

- We provide round the clock customer support

- Convenient online submission

- Thorough peer review

- Inclusion in PubMed and all major indexing services

- Maximum visibility for your research

Submit your manuscript at www.biomedcentral.com/submit
Biomed Central 